\title{
Sklenár, Robert John, Plant of a Strange Vine. "Oratio Corrupta” and the Poetics of Senecan Tragedy, De Gruyter, Berlin/ Boston, 2017, 99 pp. ISBN: 978-3110517729.
}

\author{
Martin M. Vizzotti \\ Universidad Nacional de La Plata, Argentina \\ vizzottim@gmail.com
}

Robert J. Sklenár es Professor y Associate Head Department of Classics en la University of Tennessee, Knoxville, EE.UU. y autor de numerosos artículos de la especialidad, entre ellos "Lucan the Formalist", en Brill's Companion to Lucan, ed. Paolo Asso, Leiden and Boston, 2011, 317-326; "Sopor y ebriedad: puntos de contacto entre Eneida 9 y Eneida 2", Auster 18, (2013), 7-13; "Nihilistic Cosmology and Catonian Ethics in Lucan's Bellum Civile", AJP 120, (1999), 281-296 y "La République des Signes: Caesar, Cato, and the Language of Sallustian Morality", TAPA 128, (1998), 205-220. También ha escrito un importante libro sobre Lucano The Taste for Nothingness. A Study on virtus and Related Themes in Lucan's Bellum Civile, Ann Harbor, Michigan UP, 2003. El trabajo que nos compete está organizado del siguiente modo: Chapter OneLetter 114 and the Poetics of Decadence, 1-17; Chapter Two- A Senecan Reading of Seneca's Oedipus, Part I: Language and the Diseased Animus: The Discourse of Oedipus, 18-55; Chapter Three- A Senecan Reading of Seneca's Oedipus, Part II: Language and the Diseased Cosmos, 56-91; Chapter Four-Seneca and Neronian Aesthetics, 92-96; Bibliography, 97-98; Subject Index, 99.

Esta obra se presenta, ya desde sus palabras liminares, como la continuación natural de primer libro de nuestro autor, The Taste for Nothingness. A Study on virtus and Related Themes in Lucan's Bellum Civile, en el cual propone, distanciándose de las lecturas más en vogue de la época (especialmente Henderson (1988), Masters (1992) y Bartsch (1997)) que Lucano despliega en Pharsalia un mundo convulsionado y un universo irracional y anti-estoico pero cuyo andamiaje se presenta a través de una poética cohesiva y organizada. Es decir, la casualidad que gobierna este universo (Mentimur regnare Iovem Luc. 7.447) no implica necesariamente que Lucano no desarrolle y exponga su tesis de manera sólida y sistemática ni le impide representar de manera coherente un universo incoherente e irracional.

El capítulo uno analiza de manera minuciosa y precisa la epístola a Lucilio $\mathrm{n}^{\circ} 114$, la cual resulta programática para el análisis de la poética trágica senequiana no sólo por su contenido sino por su forma: en efecto, como es común en la crítica de las obras del mal llamado "siglo de plata de la literatura latina", la epístola 114 fue acusada de carecer de una estructura sólida, de una organización armónica y de una sistematización expositiva (argumentos también habituales en las críticas a Séneca tragicus). El autor comienza destacando la aparente contradicción entre los conceptos volcados por Séneca en esta carta y los métodos y estrategias estéticas que despliega en su obra trágica, por lo que estaríamos ante una condena implícita a su propia obra poética e incluso a gran parte del estilo de su obra filosófica. Por supuesto que esto no es así, la epístola 114 puede ser considerada como un negativo del programa poético senequiano: si los preceptos y especulaciones respecto a las relaciones entre el discurso, la personalidad y el medio social son correctas, la propia epístola sería un claro ejemplo de lo que se está señalando en ella. 
Sklenár detecta que, dentro de la exposición voluntariamente dispersa de la carta, es posible distinguir un sistemático catálogo de los vicios morales y estéticos de la época y de la relación de éstos con las conductas y los estilos literarios de quienes lo practican/ padecen. A lo largo de la exposición se analiza, siguiendo a Salustio, la tesis de la subordinación del ingenium al animus; hasta tal punto esto es así que, en aquellos individuos desestabilizados, las alteraciones en el animus se reflejan no sólo en su obra sino también in corpore, -talis hominbusfuit oratio qualis vita. Ep. 114.1-, y como ejemplo paradigmático Séneca recurre, como suele hacerlo en su prosa, al habitus decadente de Mecenas. El análisis se centra luego en las características del discurso decadente y es aquí donde el Prof. Sklenár nos ofrece el punto central de su exposición y señala, quirúrgicamente, el corazón de la tesis: Séneca es un poeta decadente, conscientemente decadente (del mismo modo que Atreo es un artista conscientemente criminal) y la epístola 114 es, precisamente, un decadente tratado sobre la decadencia, entendiendo por decadencia cierto efecto estético particular, deliberado y calculado.

La caricatura de Mecenas, nos dice el Prof. Sklenář, no logra eclipsar otros rasgos del personaje que se vislumbran dentro de la argumentación de la epístola: dentro de la enumeración minuciosa de sus vicios, literarios y personales, el propio Séneca reconoce que la ostentación flagrante de estos tenía, en Mecenas, como intención principal generar efectos estéticos y configurar un personaje, -Quomodo Maecenas vixerit notius est quam ut narrari nunc debeat quomodo ambulaverit, quam delicatus fuerit, quam cupierit videri, quam vitia sua latere noluerit. Ep. 114. 4-. Luego del análisis de esta cuestión, se señala cómo el propio Séneca ha introducido, calculadamente, dentro de la composición de la epístola, los mismos procedimientos de esta oratio corrupta que condena con la intención de lograr, precisamente, efectos estéticos particulares: aparecen en la composición senequiana sensus audaces o arcaísmos que se yuxtaponen abruptamente con el sermo bumilis y cuestiones banales (114. 12-14). Nuestro autor rechaza, entonces, las infundadas acusaciones de un titubans calamus como efecto estilístico involuntario o descuidado y extrae de esta epístola ciertas premisas rectoras para su análisis del Oedipus: 1) el discurso decadente es el producto de un animus enfermoy 2) este animus es el producto de un entorno cívico también enfermo. Los capítulos siguientes analizarán el animus de Edipo como una de las características propias del anti-héroe senequiano y su entorno cívico como la manifestación de un cosmos irracional.

El capítulo dos analiza el discurso de Edipo y destaca desde sus primeros versos la aparición de esta oratio corrupta: Sklenáŕ nos señala cómo las estrategias discursivas y los efectos retóricos son, precisamente, aquellos señalados admonitoriamente por el propio Séneca a lo largo de la epístola 114. Por ejemplo, en la pag. 19 leemos, dentro del análisis de las inconsistencias presentes en la auto representación de Edipo: "The absence of iunctura that Seneca imputes to authors who harbor a misguided notion of stylistic masculinity (Ep. 114.15) here marks Oedipus as their polar opposite: he is psychologically, hence, verbally, incontinent." Sin embargo, las inconsistencias en el andamiaje estructural de los personajes no resultan casuales ni involuntarias, se señala constantemente en el desarrollo los numerosos y válidos ecos verbales y los paralelismos estructurales que cimentan el coherente entramado trágico. Esta atención a las calculadas inconsistencias discursivas de la obra y a las aporías retóricas a las que recurren los personajes para exponer sus obsesiones y miedos es lo que, a nuestro entender, ilumina y sostiene la tesis planteada en este volumen. El párrafo final de la segunda sección de este capítulo resulta, en sí mismo, una expresión cabal de la profundidad y precisión de la lectura que lleva a cabo el autor, por lo que nos permitimos citarlo en su totalidad:

"Dramatic irony so saturates Oedipus's discourse as to verge on absurdity if one poses a question of basic verisimilitude: how can this man not know that the murderer he describes is himself? Oedipus does, however, satisfy the expectations of decadent aesthetics: excess, mannerism, artifice. His distorted discourse is the result of a perception that, precisely because of its distorted nature, is able to apprehend a distorted reality. When he calls the traditional deities as witnesses to his curse on the murderer, he makes the future fulfillment of his curse inevitable under the laws of a nonexistent cosmic order; what he does not realize is that the curse is governed instead by the laws of his own hallucinatory cosmos, under which it has already been fulfilled. He 
has rhetorically removed himself from his dystopian reality and placed himself as an imaginary cosmic order where the sky is clear, the sea placid, and the celestial bodies execute an unvarying sequence of motions. Even if such universe did exist, he does not belong there, and that if why he fails to perceive that he is the object of his own curse: it is precisely in clear sunlight that he cannot see himself."

El capítulo continúa con esta línea de análisis destacando cómo las inconsistencias discursivas de Edipo reflejan la labilidad y el carácter tiránico de su animus así como también la adecuación de éste a un universo casual e irracional.

Una de las características principales del Oedipus de Séneca es el original diálogo que se plantea con el Oedipus Tyrannus a través del apartamiento consciente del tratamiento sofocleo, tanto en lo que respecta al héroe como al mito. La lectura del Prof. Sklenář agrega un nuevo matiz, un nuevo color, si se quiere, a esta línea de interpretación planteando que, mientras el héroe de Sófocles se alza reivindicado como individuo a medida que su honra y su posición pública se derrumban, el Edipo de Séneca es incapaz de eludir la inexorable maraña psicológica, existencial y discursiva en la que se encuentra atrapado. Lo patético y lo trágico conviven en la escena final de la obra, donde el discurso final de Edipo es un "[...] triumph of decadent aesthetics, with its combination of contrived form and strained, even chaotic sense."

El capítulo tercero analiza la relación entre este cosmos enfermo y el discurso trágico. La conturbación existencial y cósmica están presentes, como ya ha destacado nuestro autor anteriormente, desde los primeros versos de la obra donde ya puede apreciarse el proceso de disolución entre los límites ordenadores del mundo: día y noche, cielo e infiernos y, por supuesto, las relaciones humanas y familiares se ven entremezclados de manera promiscua. El desarrollo de la argumentación nos muestra las relaciones internas y los procesos retóricos y estructurales presentes en el discurso que dan cuenta de este proceso semántico y diegético, discurso trágico y disolución universal van de la mano. En este universo nihilista (entendiendo el nihilismo como la manifestación de la vacuidad y la trivialidad de la existencia, y la consecuente conciencia de este hecho) y enfermo un animus aegrotus no erra: "The pedigree of aeger animus as a term for mental instability stretches all the way back to Ennius, animus aeger semper errat, but here the sense is reversed: instead of misperceiving reality, the sick mind perceives reality accurately [...] Likewise the animi of Oedipus and the chorus accurately perceive their cosmological environments precisely because they are infected in the fashion described by Letter 114, and they are members of an aegra civitas both in the extended sense employed in the document and in a literal sense." El análisis de las escenas de adivinación y necromancia continúa con estos lineamientos hermenéuticos destacando, como ya hemos mencionado, la coherente representación poética de un universo enfermo e irracional. La ternera eviscerada es la encarnación del universo enfermo, mutatus ordo est (...) natura versa est. Nulla lex manet utero. (Oed. $366 \& 371$ ). El autor destaca la resonancia, en el verso 366, de Lucrecio y Manilio, el primero defendiendo la racionalidad del universo epicúreo, carente de propósito o voluntad, pero regular y regulado, mientras que el segundo proclama que, precisamente, es esa regularidad astronómica la prueba de la divinidad y racionalidad del universo: las entrañas convulsionadas de la víctima revelan la cancelación del cosmos de Manilio y las palabras finales de Manto son, ni más ni menos, que un adynaton estoico, que va desde lo universal (natura versa est) a lo particular (Nulla lex manet utero). La macabra ceremonia de necromancia termina por desintegrar de manera efectiva los límites, de por sí ya difusos, entre la tierra y los infiernos.

Un poco más adelante, el autor destaca cómo las actitudes de Edipo ante cada nueva información que recibe, sus bravatas y su facilidad para recurrir a la tortura como instrumento disuasivo, revelan en detalle su animus desestabilizado y tyrannicus. Particularmente original es la lectura del discurso de Layo, quien revela, aun después de la muerte, otro ánimo desequilibrado y furioso (ni siquiera los muertos, en la tragedia de Séneca, son capaces de deponer sus iras y sus deseos de venganza - lacer/Pentheus tenetque saevus etiamnunc iras (Oed.317-318)): Layo erra también, al igual que su hijo, al vociferar rábido su oráculo y sus predicciones. El capítulo cierra con un comentario sobre la inadecuación de los mesurados preceptos vertidos por el coro en sus intervenciones finales, ya que, al ser proferidos en el marco de este particular universo trágico su significado 
se ve alterado radicalmente por las propias condiciones de enunciación: "The final lyric utterance, then is not one of serene acceptance but of weary resignation to a sadistic Fate that presides over a cosmos of atrocities."

Tomando al Oedipus como sinécdoque que, por supuesto, no agota las posibilidades hermenéuticas de la tragedia senequiana, en el cuarto y último capítulo Sklenář extiende las posibilidades de su enfoque particular no sólo al resto de la tragedia de Séneca, sino también a los otros dos exponentes de la literatura neroniana: Lucano y Petronio. Séneca, visto desde esta perspectiva, se alinea de manera mucho más fluida y armónica con la obra de estos dos autores, no sólo por la originalidad poética y la voluntad manifiesta de apartarse, en muchos casos violentamente, de los cánones estéticos establecidos sino también por el carácter revulsivo de sus posturas artísticas. Es más, dado que resulta muy probable que la fecha de composición del Oedipus anteceda por varias décadas a la de las Epistolas a Lucilio, la carta 114 contemplaría, entonces, el programa poético del autor en retrospectiva, y, por lo tanto, se podría afirmar que, en términos estéticos, fue Séneca quien allanó el camino a las extravagancias literarias de su sobrino y del arbiter elegantiae de Nerón.

En definitiva, nos hallamos ante una lectura original y minuciosa que sigue y expande la postura hermenéutica que el Prof. Sklenár ha sostenido en sus trabajos anteriores pero que ofrece, a su vez, una nueva puerta de acceso no sólo a la obra poética y filosófica de Séneca, sino que también permite acceder a nuevas lecturas de los otros dos autores fundamentales de este convulsionado período histórico y literario. 